\title{
Implementation of lean manufacturing technologies as a resource for sustainable development of a commercial bank
}

\author{
Irina Kolchurina ${ }^{*}$, Olga Prihodko, Tatyana Volkova, and Kira Ponomareva \\ Siberian State Industrial University, Kirov Str., 42, 654007 Novokuznetsk, Russia
}

\begin{abstract}
The tough regulatory requirements of the Central Bank of Russia, competition with transnational banks and a reduction in the volume of issued loans made it necessary to develop measures aimed to increase the efficiency of a regional commercial bank. In this regard, search for new management methods, implementation of analysis tools and improvement of a financial organization activity are relevant. The article proposes to optimize business the processes of the management system of the regional commercial bank by using lean manufacturing tools. The advantages and usefulness of a value stream map for business processes analysis and optimization are considered and substantiated. The tool was implemented in relation to the business process of the commercial bank «Lending to individuals». The time of operations and interoperation intervals was determined, risk analysis was made, and measures were proposed to improve the process. The economic efficiency of corrective measures was calculated.
\end{abstract}

\section{Introduction}

The Russian banking system has the largest number of participants in the world and today it is represented by almost five hundred commercial banks, and over the past ten years, that number has decreased by more than half.

Regional banks cannot fully use their potential, because the activity of large, medium and small regional banks are regulated in the same way in Russia, and the specifics of the banks activities is not taken into account.

Experts admit that regional banks are ineffective, and this constrains the development of regions in the country. $80 \%$ of banking assets are controlled by Moscow banks, although $90 \%$ of GDP is created in the regions.

As a rule, a limited area of activity of regional banks (within one region) leads to a limited client base that in turn affects an interest rate and terms of lending and makes it impossible to compete with transnational banks. A significant difference in size of the authorized capital of transnational and regional banks does not allow a regional bank to reach a new level of development.

It should also be noted there are severe restrictions that include the regulatory requirements of various governing bodies and levels of government under which regional

\footnotetext{
* Corresponding author: ira-kolchurina@yandex.ru
} 
credit organizations operate. Therefore, an intention of a regional bank to meet and exceed customer requirements is often impracticable.

On the other hand, size and structure are the advantages of regional banks in comparison with multinationals. It is easier for small banks to adapt business models to market changes. In addition, less complex governance structure of small banks provides more efficient management.

In this regard, it is relevant for a regional bank to search for methods to optimize activity and implement new management methods including lean production tools $[1,2]$.

\section{Methods and types of the Earth's remote sensing}

The implementation of lean manufacturing approaches and the increase in labor productivity is the main idea of the state program «Increasing labor productivity», under which the state co-finances the enterprises investments to optimize production processes.

The implementation of lean manufacturing approaches is consistent with the sustainable development goals formulated in the «Resolution adopted by the UN General Assembly on 25 September, 2015 by No. 70/1. Transforming Our World: The 2030 Agenda for Sustainable Development «and directly addresses the targets set by the following» Sustainable Development Goals 2030»: "Goal 8. To promote sustained, inclusive and sustainable economic growth, and productive employment and decent work for all; 8.2 To achieve increased productivity in the economy by means diversification, technical modernization and innovation, including focus on high value added and labor-intensive sectors; Goal 9. To build resilient infrastructure, promote inclusive and sustainable industrialization and innovation; Goal 12. To ensure the transition to sustainable patterns of consumption and production».

It is known that introduction of the concept of «lean manufacturing» or lean-technologies allows shortening of duration of a production cycle and labor costs while maintaining or increasing productivity and profits, creating a flexible production system that provides quick respond to changing consumer demands.

The goals of lean manufacturing are achieved by reducing or eliminating losses of products manufacturing process (or services providing).

Considering the essence of the concept of lean production - value creation and losses minimization - it is advisable to study and develop measures to optimize the business processes of a commercial bank using the most important tool called «Value Stream» [3$8]$.

Value stream maps are material and information flows represented on paper in the course of value creation and make it possible to trace a production chain from the Consumer to the Supplier.

The considered approaches and tools were used to analyze and develop the measures for improving the business processes of the regional commercial bank.

In order to analyze the indicators of business processes, the material and information flows of the external and internal context of the bank was studied. Material flows are areas of activity (current, investment and financial). Each section has income and expense parts, which are managed by the bank. As for the external context of information flows, they are a state of the economy of the country and the region, counterparties. The internal context includes the bank's departments: the department of lending to legal entities and individuals, the mortgage-lending department, the operational department.

In order to analyze the processes of the commercial bank, the stages of lending processes for individuals, legal entities and mortgage lending were studied.

So, in the period from 11 to 25 November 2019 , the data for study was assembled in the additional office of the regional bank. The object of the study was the services provided by 
the bank to legal entities and individuals. The time interval of the study was determined by the traditional workload of the additional office in the second - third week of the month.

In order to clarify the data received and additional information assembled, observation was carried out within 3 working days with taking notes on the managers work in the consumer lending department in the period from 17 to 19 February 2020.

The observation results were recorded in a checklist, and then processed using the Microsoft Excel software product.

Microsoft Visio (MV) software product was used to develop value stream maps. The developers of the MV program have provided a platform for designing value stream diagrams (maps) with the necessary blocks, pointers, arrows, signs, etc. The presence of ready-made blocks greatly simplifies and speeds up the process of developing maps.

\section{Analysis of the main ERS data sources for the DEM development}

Based on the description of lending business processes, value stream maps were developed for each process.

The value stream map for the retail lending process is presented in Fig. 1. The figure shows how much time is spent on losses. If all losses are minimized or eliminated, the organization will need less material and expenses to complete the process.

The Lending to Individuals process includes seven sub-processes:

1) determining a type of a loaner;

2) acceptance of an application;

3) review of a package of documents;

4) checking a package of documents by a security service;

5) making a decision on the possibility of lending;

6) execution of a loan agreement;

7) opening a loan account and issuing a loan.

Each sub-process was considered separately in order to determine the most critical stage in terms of the amount of losses.

Before starting the process «Lending to individuals», the first loss is to determine the qualifications of a borrower, the duration of the stage is 40 minutes. It should be mentioned that it is not possible to start the next sub-process without completing this.

Process losses include:

- unnecessarily spent time by the manager on formation of an initial package of documents of a borrower;

- unnecessary time spent on reconciliation of copies of provided documents with the originals, their verification and transfer the package of documents received from a borrower to a credit manager.

At the stage "Checking a package of documents by a security service», a consultant manager performs the following operations: checking documents provided by a borrower; making a preliminary calculation of a credit limit; verification copies of the documents provided with the originals and their notarization with the inscription «Copy is correct: full name, date, signature». At the same time, the employee pays special attention to determining the authenticity of the documents, as well as the ensuring conformity of a borrower's personality with the documents provided, forms a primary credit dossier. Consequently, when considering an application, there is a duplication of operations. The loss of working time for performing these operations cannot be reduced to zero, because in this case, there will be a violation of the requirements of the regulatory documents regulating work of the bank. But possibilities for reducing the duration of operations were identified during the study. 
So significant time is spent on transferring a borrower's documents between officials and departments of the bank.

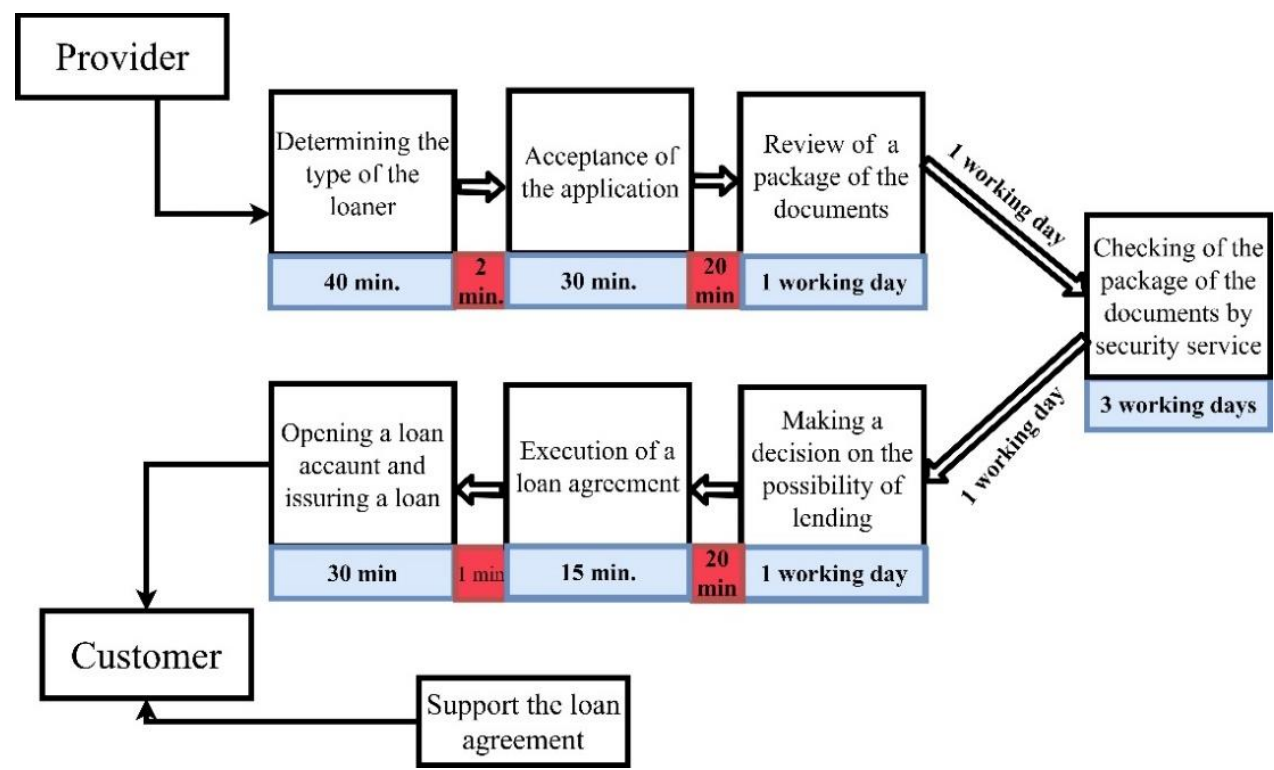

Fig. 1. Value stream map of a current state of the process «Lending to individuals»

Based on analysis of the value stream map, it can be noticed that the duration of the process «Lending to individuals» is 5 working days and 130 minutes, but taking into account losses it is more than seven working days ( 40 minutes +2 minutes +30 minutes +20 minutes +1 working day +1 working day +3 working days +1 working day +20 minutes +30 minutes +1 minute +30 minutes $=7$ working days and 173 minutes), with 2 working days and 43 minutes are spent on interoperation intervals.

In order to eliminate or minimize the time losses and expenses of the bank, the organization has to perform a number of activities. Before performing the operations of the organization activity, it is necessary to consider the risks connecting with the process.

So in carrying out the study, the risks of the process «Lending to individuals» were considered. To assess the identified risks of sub-processes, a risk assessment matrix was developed.

Based on the analysis of the identified risks of the process «Lending to individuals», measures were developed to optimize significant and critical risks.

In order to minimize or eliminate most of the losses, the bank has to perform the following measures:

- reduce the interoperability intervals at such stages as «Determination of a borrower's qualifications" and "Acceptance of an application" by automating the application process;

- to determine conditions for verification of a customer's documents by a security service (for example, to determine the loan amount for which a borrower applies);

- to reduce the duration of document inspection by a security service;

- a manager should carry out preliminary preparations for a final meeting with a borrower. If all the documents are ready to be filled out by a borrower, the time at such stages as «Execution of a loan agreement» and «Opening a loan account and disbursement of funds» will be reduced.

If all the proposed measures are fulfilled, the organization will eliminate losses not related to the process and minimize losses connected with the process of «Lending to individuals». 
Fig. 2 shows a map of expected state of the value stream of the process «Lending to individuals». The value stream map shows how much time it takes to complete all the activities mentioned above. To complete the process «Lending to individuals», the bank will need 6 working days and 103 minutes, taking into consideration losses.

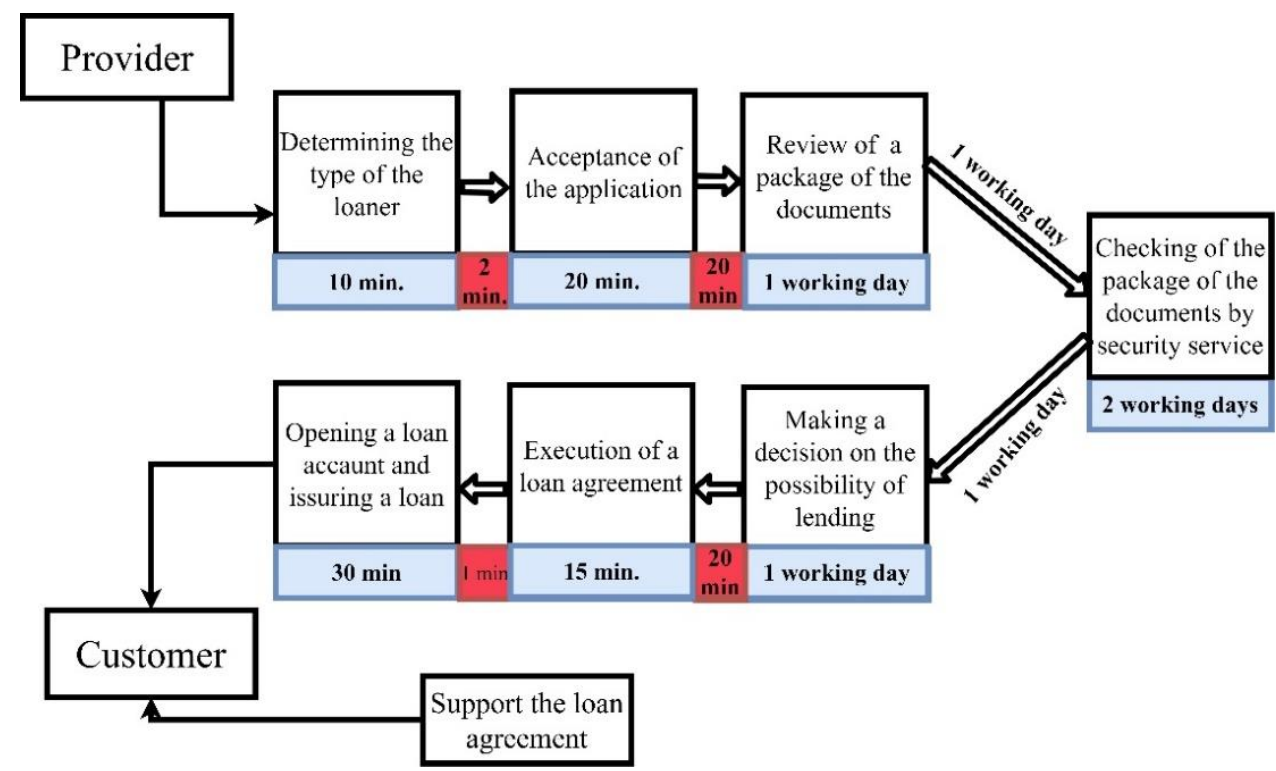

Fig. 2. Value stream map of an expected state for the process «Lending to individuals»

During the analysis of the map of an expected state of the value stream, it can be noticed that the time of operations for processing and execution can be significantly reduced. It will make possible to process more applications for loans and increase the profit from the implementation of business processes.

So now the bank workers spend 7 working days and 173 minutes (duration of the current state) on lending to individuals, but in case of implementation of measures (duration of the expected state), this time will be reduced to 6 working days and 103 minutes. As a result, the bank will be able to increase its income by $22,7 \%$ after implementation of measures for optimization of lending to individuals process. It can be concluded that the measures are effective.

\section{Conclusions}

1. In the face of fierce competition with transnational banks, limited resources and regulatory requirements for banking organizations, it is urgent for a regional bank to search for methods to optimize activity and implement new management methods, including lean manufacturing tools.

2. Regional banks, which are usually small, find it easier to adapt business models to market changes, and their less complex governance structure can be considered as a source for more efficient management.

3. Based on analysis carried out during the study, it was decided to use the mapping of the value creation stream for the process «Lending to individuals» for a visual representation of the current state of the process. Value stream mapping is the most important component of Lean and most of the Lean tools as it identifies and eliminates losses. It is the most common method used to identify losses within a production flow of a particular product. It is necessary 
to make a flow meet the requirements by minimizing losses and improving the synchronization of work. In addition, value stream mapping is a fairly simple and intuitive graphical diagram that depicts the material information flows required to provide a product or service to a final consumer. The value stream map makes it possible to identify the bottlenecks of a flow and specify its losses in a production process, based on a flow analysis [8].

4. The implementation of lean manufacturing approaches and increasing labor productivity is the main idea of the state program «Increasing labor productivity» and is consistent with the sustainable development goals formulated in the «Resolution adopted by the UN General Assembly on 25September, 2015 by No. 70/1. Transforming Our World: The 2030 Agenda for Sustainable Development» and directly addresses the challenges identified by Goals 8, 9 and 12 .

5. Based on the value stream map of the current state of the process «Lending to individuals», the losses and sources for optimization of time spent on the process were identified, measures for improvement were developed, on the basis of the value stream map the future concept of the process was developed. The value stream map shows the reduction in time taken to complete the proposed activities. The proposed activities are economically feasible.

6. The use of lean manufacturing tools is reasonable and effective to improve the activity of a regional commercial bank.

\section{References}

1. S. Drucker, M. Puri, Handbook of Empirical Corporate Finance (2007)

2. B. Li, M. Zou, Y. Guo, Social and Behavioral Sciences, 138 (2014)

3. E. Suciu, The Annals of The «Stefan cel Mare» University of Suceava, 11 (2011)

4. P.M. Masuti, U.A. Dabade, Materials Today: Proceedings, 19 (2019)

5. B. Singh, S.K. Garg, S.K. Sharma, International Journal of Advanced Manufacturing Technology, 53 (5-8) (2011)

6. D. Stadnicka, P. Litwin, International Journal of Production Economics, 208 (2018)

7. M. Rother, Learn to see business processes. Value stream mapping practice (2005)

8. P. Roh, A. Kunz, K. Wegener, CIRP Journal of Manufacturing Science and Technology, 25 (2019) 